\title{
Genetik Algoritma ve Denge Optimizasyon Algoritması (EO) kullanılarak Yıldırım Darbesinin Parametre Tahmini
}

\section{Lightning Impulse Parameter Estimation using Genetic Algorithm. (GA) and Equilibrium Optimizer (EO) Algorithm}

\author{
Mustafa ŞEKER ${ }^{*}$ iD , Harun IŞIK ${ }^{2}$ iD \\ ${ }^{1}$ Hafik Kamer Örnek Meslek Yüksek Okulu, Ulaştırma Hizmetleri Bölümü, Sivas Cumhuriyet Üniversitesi, Sivas, \\ Türkiye \\ 2 Elektrik-Elektronik Mühendisliği Bölümü, Sivas Cumhuriyet Üniversitesi, Sivas, Türkiye \\ (20209233011@cumhuriyet.edu.tr, mustafaseker@cumhuriyet.edu.tr)
}

$\ddot{O}_{z}$ etçe-Yıldırımlar, atmosferik değişimlere bağlı olarak meydana gelen, enerji sistemleri ve canlılar üzerinde birçok olumsuz etkiye neden olan doğa olayıdır. Bu çalışma, genetik algoritma (GA) ve Metasezgisel optimizasyon algoritmalarından denge optimizasyon (EO) algoritması kullanılarak yıldırım akımı dalga formunu tanımak için literatürde sunulan darbe ve çift üstel fonksiyonlarının parametrelerinin optimizasyon tabanlı eğri uydurma yöntemi ile hesaplanmasını temel bir yaklaşım sunmaktadır. Çalışmada, Yıldırım akımı dalga formu olarak Dresden Yüksek Gerilin Test Teknolojisinden (IP176/12S) deneysel olarak ölçülen 10/350 $\mu$ s' lik ve 20,8 kA genliğe sahip yapay yıldırım akım dalga formu kullanılmıştır. Bu dalga formundan faydalanılarak darbe ve çift üstel fonksiyon parametreleri optimizasyon algoritmaları yardımıyla hesaplanmıştır. Elde edilen sonuçlar, darbe fonksiyonunun yapay yıldırım akımı dalga formunu çift üstel fonksiyona göre daha iyi tanımladığını göstermektedir. Darbe fonksiyonu ile hesaplanan parametre değerleri karşılaştıııldığında, $\mathrm{EO}$ ile hesaplanan fonksiyon değişkenlerinin $\mathrm{STD}=5.354 \mathrm{e}-2, \mathrm{RE}=2.35 \mathrm{E}-10, \mathrm{MAE}=5.44 \mathrm{e}-12$ ve $\mathrm{RMSE}=4.48 \mathrm{E}-6$ ile GA'ya göre daha iyi sonuçlar verdiği görülmektedir.

Anahtar Kelimeler: Yıldırım dalga formu, darbe fonksiyonu, çift üstel model, Genetik algoritma, Denge Optimizasyon algoritmasl.

\begin{abstract}
Lightning is a natural phenomenon that occurs due to atmospheric changes and causes many negative effects on energy systems and living things. This study presents a basic approach for calculating the parameters of pulse and double exponential functions presented in the literature by optimizationbased curve fitting method to recognize the lightning current waveform using equilibrium optimization (EO) algorithm from meta-heuristic optimization algorithms and genetic algorithm (GA). In the study, artificial lightning current waveform with $10 / 350 \mu$ s and $20.8 \mathrm{kA}$ amplitude measured experimentally from Dresden High Voltage Test Technology (IP176/12S) has been used as lightning current waveform. By using this waveform, pulse and double exponential function parameters are calculated with the help of optimization algorithms. The results show that the pulse function describes the artificial lightning current waveform better than the double exponential function. When the parameter values calculated with the pulse function are compared, it is seen that the function variables calculated with EO give better results than GA with $\mathrm{STD}=5.354 \mathrm{e}-2, \mathrm{RE}=2.35 \mathrm{E}-10, \mathrm{MAE}=5.44 \mathrm{e}-12$ and $\mathrm{RMSE}=4.48 \mathrm{E}-6$.
\end{abstract}

Keywords: Lightning waveform, pulse functon, doube exponential function, Genetic algorithm, Equilibrium Optimizer Algorithm. 


\section{GİRIŞ}

Yıldırımlar atmosferik değişimlere bağlı olarak ortaya çıkan en yaygın doğa olayıdır (Paolone ve ark., 2003). Bu doğa olayı zaman zaman insan yaşamını olumsuz etkilemekte can kayıpları, elektrik şebekelerinde ve haberleşme sistemlerinde ciddi zararlar başta olmak üzere birçok olumsuz etkiye neden olmaktadir (Paolone ve ark., 2001; Borghetti ve ark., 2004)

Gelişen teknolojiye paralel olarak yıldırımların neden olduğu olumsuz etkilere karşı daha fazla koruma ihtiyacı ortaya çıkmıştır. Yıldırım aşırı gerilimlerinden korunmaya yönelik araştırmalar ve mühendislik uygulamalarda ancak onun karakteristik yapısının daha iyi anlaşılması ile mümkündür.

Yıldırım darbelerinin karakteristik yapısı birçok araştırmacı tarafindan incelenmiştir. Yapılan çalışmalarda yıldırım akımının yük ve tepe gerilimi arasında ilişki kurulabileceğini gösterilmiştir (Berger ve ark., 1975; Anderson ve Eriksson, 1980). İki ölçüm istasyonundan eş zamanlı deneysel çalışmalar gerçekleştirilerek yıldırım darbesinin elektriksel karakteristiği incelenmiştir (Lin ve ark., 1979). Ölçüm kulelerinden gerçekleştirilen deneysel çalışmalar ile yıldırım çarpmalarında oluşan geçici davranışlar gözlemlenmiştir (Rakov, 2001). Gerçekleştirilen bu çalışmalar, yıldırım çarpmalarının modellenmesi, yıldırım deşarjlarının parametre tahmini ve yıldırımdan korunma çalışmalarında kullanılmıştır (Willett ve ark., 1989; Leteinturier ve ark., 1990; Gamerota ve ark., 2012). Bu çalışmalar uluslararası standartlarda yıldırımdan korunma yönetmeliklerinin oluşturulmasına katkılar sağlamıştır. Y1ldırım darbeleri IEC 62305-1 Ed.2 ve IEEE uluslararası standartlarına göre tanımlanmaktadır (Lewin ve ark., 2008; Protection againts Lightning Part 1, 2010).

IEC standartlarında yıldırım akımının genel dalga formu yapısı Şekil 1' de gösterilmiştir. Burada, Ip akımın pik değerini, $\mathrm{t} 1$ akımın pik değerinin $\% 90$ değerine ulaştığı durumdaki zamanı, t2 değeri ise pik değerinin yarıya düşmesi için geçen süreyi temsil etmektedir. Bu dalga formu için akımın maksimum pik değerine bağlı olarak $10 / 350 \mu \mathrm{s}, 1.2 / 50 \mu \mathrm{s}$ ve $8 / 20 \mu$ s gibi farklı standartlarda kullanılmaktadır. $\mathrm{Bu}$ ifadelerde birinci parametre yıldırım akımının maksimum değere ulaşması için geçen süreyi (current rise time), ikinci ifade ise akımın maksimum genlik değerinin yarı düşmesi için geçen süreyi (decay time) ifade etmektedir.

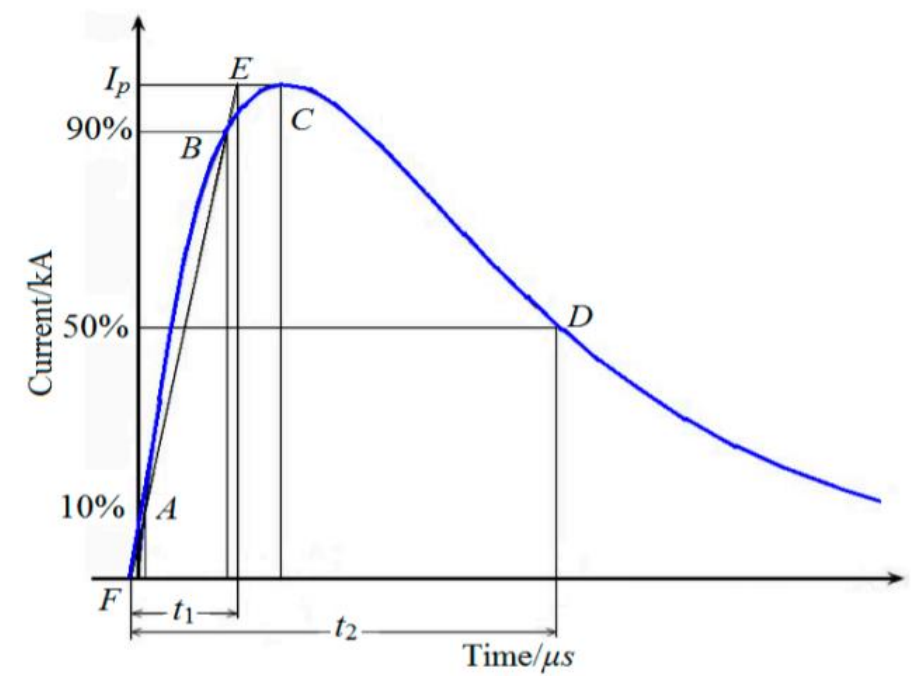

Şekil 1. IEC standardına göre genel yıldırım akımı dalga formu

Özel sistemleri kullanılarak yıldırım akımı dalga formlarının ölçülmesi mümkündür. Fakat gerçek zamanlı ölçülen yıldırım dalga formların ölçüm sistemlerinin yüksek maliyet içermesinin yanı sıra gürültü, yansıma ve çözünürlük problemleri gibi bazı dezavantajlara sahiptir. Her ne kadar günümüzde geliştirilen birçok teknik bu dezavantajları gidermek için kullanılsa da (McComb ve Lagnese, 1991; Wong ve ark., 1999; Al-Hasawi ve El-Naggar, 2003), gerçek zamanlı yıldırım darbesinin belirsizlik içermesinden dolayı karakteristiğini tanımlamak oldukça zor olmaktadır. Tanımlanan standartlara göre, çeşitli jeneratörler ve darbe üretici devreler kullanılarak laboratuvar ortamında yapay yıldırım dalga 
formunun elde edilmesi mümkündür. Laboratuvar ortamında üretilen yapay yıldırım dalga formu kullanılması herhangi bir gürültü ve yansıma problemi içermeyeceği için farklı yıldırım fonksiyonlarının karşılaştırılması, belirsizliklerin çözümü ve dalga formu parametrelerinin belirlenmesi açısından da daha faydalı olmaktadır ( Elrodesly, 2010)

$\mathrm{Bu}$ çalışma, laboratuvar ortamında üretilen 10/350 $\mu \mathrm{s}^{\prime}$ lik 20,8 kA'lik yıldırım akımı dalga formu kullanılarak, Genetik Algoritma ve Denge Optimizasyon algoritması yardımı ile yıldırım akımı dalga formunu tanımlamada yaygın olarak kullanılan Çift üstel (Double Exponential) model ve Darbe (Pulse) fonksiyonları için matematiksel parametrelerinin tahmini gerçekleştirilmiştir. Sonuçlar istatistiksel olarak değerlendirilerek, Yıldırım akımı dalga formu parametrelerinin belirlenmesinde optimizasyon algoritmalarının performansı ve yapay yıldırım akımını tanımlamada kullanılabilecek en uygun matematiksel model belirlenmiștir.

\section{YAPAY YILDIRIM AKIMI DALGA FORMUNUN ÖLÇÜMÜ}

$\mathrm{Bu}$ çalışmada yapay yıldırım akımı dalga formu olarak, Dresden Yüksek Gerilim Test Teknolojisi laboratuvarından (IP176/12S) deneysel olarak ölçülen 10/350 us' lik ve 21,5kA genliğe sahip yıldırım akımı dalga formu kullanılmıştır (Machts ve ark., 2019). Deneysel sistemde Jeneratör 12 anahtarlamalı tekli kapasitör içermektedir. Her bir yüksek gerilim kapasitörü $175 \mu \mathrm{F}$ kapasite değerine sahiptir ve 12 $\mathrm{kV}$ gerilim ile yüklenebilmektedir. Kapasitör gruplarının değiştirilmesi ile akım darbe jeneratörü ayarlanarak farklı seviyelerde yıldırım akımı darbesinin elde edilmesi de mümkün olmaktadır. Deneysel olarak ölçülen 10/350 $\mu \mathrm{s}^{\prime}$ lik ve 21,5 kA genliğe sahip yıldırım akımı dalga formu Şekil 2'de sunulmuştur.

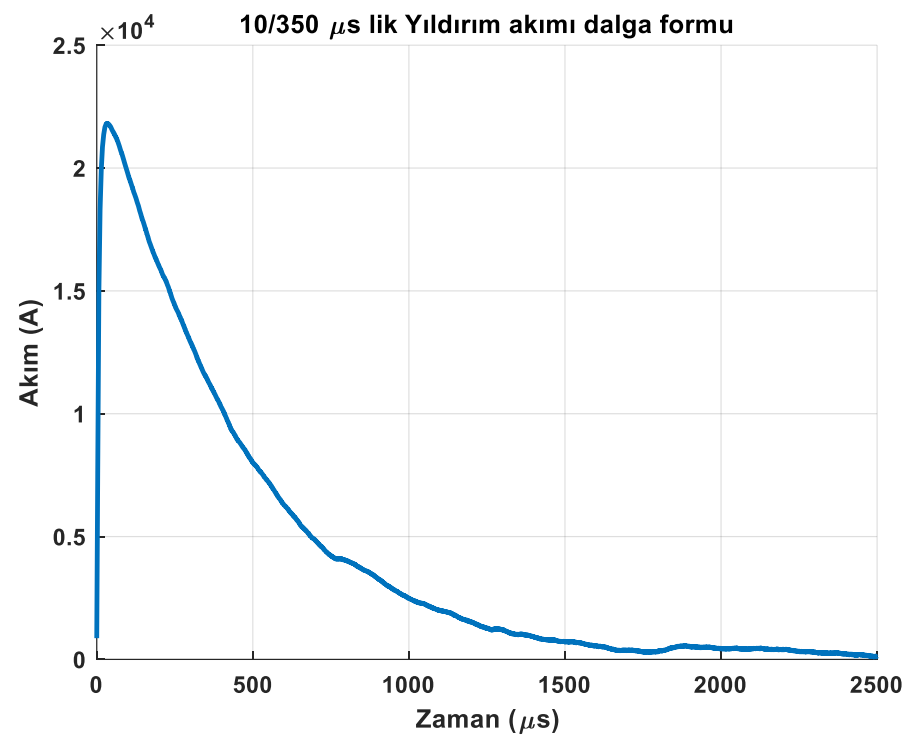

Şekil 2. Dresden Yüksek Gerilim Test Teknolojisi laboratuvarından (IP176/12S) deneysel olarak ölçülen 10/350 $\mu s^{\prime}$ 'lik yapay yıldırım akımı dalga formu.

\section{Yildirim AKIMI Dalga Formunu TANimlamada Kullanilan BenZetim FONKSIYYONLARI}

Yıldırım akımı dalga formunu tanımlamada kullanılan genel matematiksel yaklaşım (1) ifadesi ile tanımlanır. $\mathrm{Bu}$ ifadede $\mathrm{x}(\mathrm{t})$ akımın yükselme ve $\mathrm{y}(\mathrm{t})$ akımın azalma fonksiyonunu ifade etmektedir (Elrodesly ve Hussein, 2010).

$$
I(t)=I_{m a k} \cdot x(t) \cdot y(t)
$$

$\mathrm{Bu}$ genel ifadede $\mathrm{x}(\mathrm{t})$ ve $\mathrm{y}(\mathrm{t})$ fonksiyonları arasında geçiş süresince tam bir süreklilik söz konusu değildir. Bu nedenle fonksiyonlar arasındaki bütünlüğü sağlamak için düzelme faktörü kullanılır. Düzeltme faktörüne bağlı olarak (1) denklemi (2) eșitliği ile ifade edilir. 


$$
I(t)=\frac{I_{m a k}}{\eta} \cdot x(t) \cdot y(t)
$$

$\mathrm{Bu}$ ifadeden yola çıkarak bazı matematiksel fonksiyonlar yıldırım akımı dalga formunu tanımlamada kullanılmaktadır. Bu bölümde, yıldırım akımı dalga formunun matematiksel ifadesini tanımlamada literatürde en yaygın olarak kullanılan Darbe (Pulse) fonksiyonu ve Çift üstel (Double Exponential) fonksiyon ifadeleri açıklanmıştır.

\subsection{Darbe Fonksiyonu}

Yıldırım akımı dalga formunun tanımlanmasında kullanılan Darbe fonksiyonunun matematiksel ifadesi (3) eşitliği ile tanımlanır (Chen ve ark., 2002).

$$
I(t)=\frac{I_{m a k}}{\eta} \cdot\left(1-e^{\frac{-t}{\tau_{1}}}\right)^{n} \cdot e^{\frac{-t}{\tau_{2}}}
$$

$\mathrm{Bu}$ eşitlikte; Imak- akımın maksimum değerini, $\tau 1$ ve $\tau 2$ ifadeleri ise sırası ile akımın yükselme ve azalmasını tanımlayan zaman sabitlerini ifade etmektedir. $\eta$ ise düzeltme faktörüdür. Sıfır geçiş durumunda (3) eşitliğinin türevi alınarak sıfıra eşitlendiğinde ve gerekli düzenlemeler yapıldığında, düzeltme faktörünün matematiksel ifadesi (4) eşitliği ile ifade edilir.

$$
\eta=\left(\frac{n \cdot \tau_{2}}{\tau_{1}+n \cdot \tau_{2}}\right)^{n} \cdot\left(\frac{\tau_{1}}{\tau_{1}+n \cdot \tau_{2}}\right)^{\frac{\tau_{1}}{\tau_{2}}}
$$

\section{2. Çift Üstel Fonksiyon}

Yıldırım akımı dalga formunun modellenmesinde yaygın olarak kullanılan Çift üstel fonksiyonun matematikse ifadesi (5) eşitliği ile ifade edilir (Heidler ve ark., 1999).

$$
I(t)=\frac{I_{m a k}}{\eta}\left(e^{\frac{-t}{\tau_{1}}}-e^{\frac{-t}{\tau_{2}}}\right)
$$

Bu ifadede; Imak- yıldırım akımının maksimum değeri, $\tau 1$ ve $\tau 2$ sırası ile akımın yükselme ve azalma durumu tanımlayan zaman sabitleri ve $\eta$ - düzeltme faktörüdür. Çift üstel model için düzeltme faktörünü akımın maksimum değerini ayarlamak için kullanılır. (5) ifadesinin birinci türevi alınarak sıfıra eşitlendiğinde düzeltme faktörünün matematiksel ifadesi (6) eşitliği ile ifade edilir.

$$
\eta=e^{-\frac{t_{m a k}}{\tau_{1}}}-e^{\frac{t_{m a k}}{\tau_{2}}}
$$

$\mathrm{Bu}$ ifadede $\mathrm{t}_{\mathrm{mak}}$ akımın maksimum olduğu durumundaki zamanı ifade etmektedir. $t_{\text {mak }}$ ifadesi (5) denklemi ile ifade edilen Çift üstel fonksiyonunun ikinci türevinin sıfıra eşitlenmesi ile bulunur. $\mathrm{Bu}$ durumda (5) denkleminin ikinci türevi sıfıra eşitlenerek gerekli düzeltmeler yapıldığında $t_{\operatorname{mak}}(7)$ denklemi ile hesaplanır.

$$
t_{m a k}=\frac{\tau_{1} \cdot \tau_{2}}{\tau_{1}-\tau_{2}} \cdot \ln \left(\frac{\tau_{1}}{\tau_{2}}\right)
$$

\section{Yildirim AKIMI Dalga Formunu TANimlamada Kullanilan BenZetim FONKSIYYNLARI}

Bu çalışmada, yıldırım akımı dalga formunun matematiksel ifadesini tanımlamada kullanılan darbe ve çift üstel fonksiyonlarının parametre değerleri Genetik algoritma ve Meta-Sezgisel optimizasyon algoritmalarında Equilibrium (Denge) Algoritması (EO) kullanılarak belirlenmiştir.

\subsection{Genetik Algoritma (Genetic Algorithm)}

Genetik algoritmalar (GA) kompleks problemlerin ve fonksiyonların en uygun çözümünün bulunmasında kullanılan genel amaçlı araştırma algoritmasıdır (Franzel, 1993; Elmas, 2007). GA doğru çözüm hakkında herhangi bir bilgi sahibi olmadan bir başlangıç değeri oluşturur (Elmas, 2007). Daha 
sonra seçim, çapraz geçiş ve mutasyon gibi evrim operatörlerini kullanarak en iyi çözüme ulaşmaya çalışılır. Bu işlem gerçekleştirilirken başlangıç popülasyonundan başlayarak en güçlü genin hayatta kalma koşuluna göre eski bilgilerden faydalanılır. Bu şekilde tekrar eden genlerde çözümü amaçlanan karmaşık problemi çözme yeteneğinin geliştirilmesi amaçlanır. En uygun çözüme ulaşana kadar bu işlem yinelemeli olarak tekrarlanır. Bu Süreci açıklayan algoritma akış şeması Şekil 3'de sunulmuştur.

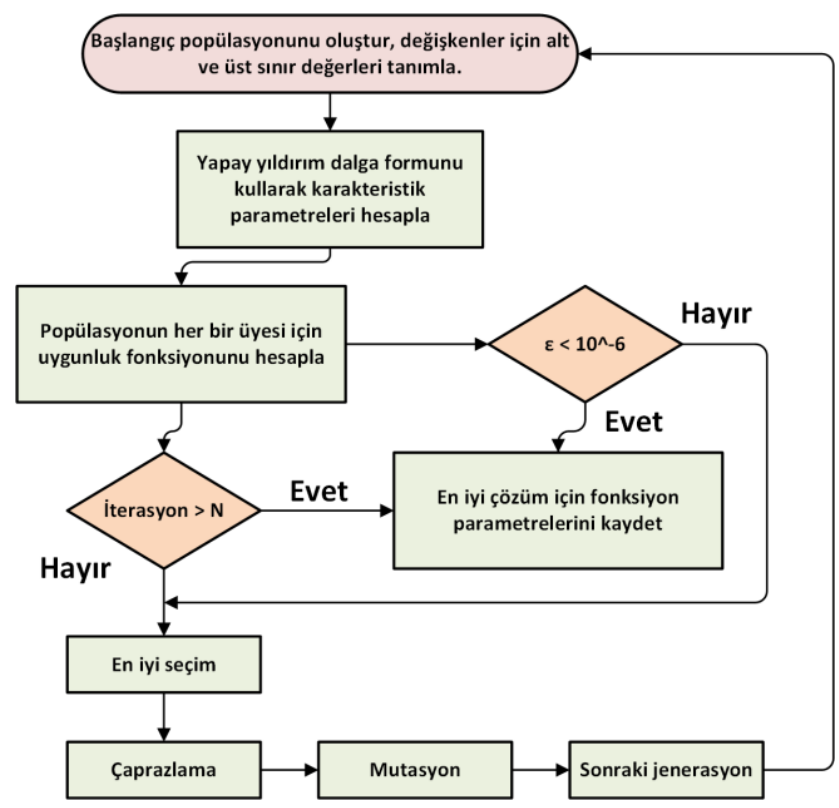

Şekil 3. Benzetim fonksiyonların parametre tahmininde kullanılan Genetik Algoritma akış şeması.

\subsection{Denge Optimizasyon (Equilibrium Optimizer-(EO)) Algoritması}

EO algoritması fizik yasalarından yararlanarak geliştirilmiş bir arama algoritmasıdır. Denge optimizasyon algoritmasının ilham kaynağı kontrol hacmi üzerindeki dinamik kütle dengesinin karşılaştırılmasıdır. Kütle denge denklemi, reaktif olmayan bir bileşenin konsantrasyonunu tanımlamak için kontrol hacmi içerisindeki çeşitli kaynakların ve sızıntı mekanizmasının bir fonksiyonu olarak kullanılır. EO algoritmasının matematiksel modeli 4 ana basamaktan oluşmaktadır (Faramarzi ve ark., 2020).

\section{Adım 1: Başlatma ve işlev değerlendirmesi}

Birçok Meta-sezgisel algoritmasında olduğu gibi, EO algoritmasında da başlangıç popülasyonun oluşturulması gerekmektedir. Popülasyonun uzay düzleminde istenilen sınır değerleri arasında arama yapabilmesi icin, alt ve ust limitlerin belirlenmesi gerekmektedir. Bu sinır değerler (8) ifadesi ile tanımlanır.

$$
\mathrm{C}_{\mathrm{i}}^{\mathrm{in}}=\mathrm{C}_{\min }+\left(\mathrm{U}^{\mathrm{b}}-\mathrm{L}^{\mathrm{b}}\right) \cdot \operatorname{rand}(\mathrm{i}), i^{n}=1,2,3, \ldots \mathrm{n}
$$

$C_{i}^{i n}, i^{n}$ partikulun başlangıç konum vektörü, rand(i) [0-1] arasında rastgele değişen vektör. $\mathrm{L}^{\mathrm{b}}$ ve $\mathrm{U}^{\mathrm{b}}$ sırasıyla değişkenlerin minimum ve maksimum sınır aralığıdır. $\mathrm{n}$ ise popülasyon sayısıdır. EO algoritmasının çalışmasında; her parçacık ve parçacı̆̆ın konsantrasyonu arama ajanı gibi çalışır. Ajanlar, denge durumuna ulaşabilmek için konumlarını iteratif olarak günceller.

\section{Adım 2: Denge Havuzu ve Adaylar $\left(\vec{C}_{e q}\right)$}

EO algoritmaları sistemin denge durumunu araştırır. EO, denge durumuna ulaşana kadar konsantrasyon seviyesi bilinmemektedir (Faramarzi ve ark., 2020). Arama algoritmasının çözüm adayları, optimizasyon işlemi sırasında tanımlanan en iyi dört parçacık ve parçacıkların konumunu aday olarak seçilir. Seçilen dört parçacı̆̆ın aritmetik ortalaması alınarak beş parçacık denge adayı olarak gösterilir. (9) eşitliği denge havuzu vektör olarak oluşturmak için kullanılır. 


$$
\begin{aligned}
& \overrightarrow{\mathrm{C}}_{\text {eq,pool }}=\left\{\overrightarrow{\mathrm{C}}_{\mathrm{eq}(1)}, \overrightarrow{\mathrm{C}}_{\mathrm{eq}(2)}, \overrightarrow{\mathrm{C}}_{\mathrm{eq}(3)}, \overrightarrow{\mathrm{C}}_{\mathrm{eq}(4)}, \overrightarrow{\mathrm{C}}_{\mathrm{eq}(\mathrm{ave})}\right\} \\
& \overrightarrow{\mathrm{C}}_{\mathrm{eq}(\text { ave })}=\frac{\overrightarrow{\mathrm{C}}_{\mathrm{eq}(1)}, \overrightarrow{\mathrm{C}}_{\mathrm{eq}(2)}, \overrightarrow{\mathrm{C}}_{\mathrm{eq}(3)}, \overrightarrow{\mathrm{C}}_{\mathrm{eq}(4)}}{4 \text { ( Değişken sayıs ) }}
\end{aligned}
$$

f , uygunluk fonksiyonu göstermek üzere, (8. c) şartı sağlanmalıdır (Faramarzi ve ark., 2020).

$$
f\left(\overrightarrow{\mathrm{C}}_{\mathrm{eq}(1)}\right) \leq f\left(\overrightarrow{\mathrm{C}}_{\mathrm{eq}(2)}\right) \leq f\left(\overrightarrow{\mathrm{C}}_{\mathrm{eq}(3)}\right) \leq f\left(\overrightarrow{\mathrm{C}}_{\mathrm{eq}(4)}\right)
$$

\section{Adım 3: Ana konsantrasyonun güncelleme kuralı}

EO algoritmasında tanımlanan $\mathrm{F}$ terimi, keşif ve sömürü işlemleri arasında bir dengeye vazifesi görür. $\lambda,[0,1]$ aralığında rastgele bir vektör olarak olmak üzere f ifadesi (9) eşitliği ile ifade edilir.

$$
\overrightarrow{\mathrm{F}}_{\text {eq }}=\mathrm{e}^{-\vec{\lambda}\left(\mathrm{t}-\mathrm{t}_{0}\right)}
$$

$t$, ifadesi iterasyon değerine bağlı bir fonksiyondur ve değeri iterasyon sayısına bağlı olarak azalır. (10.a) ifadesi $t$ değerinin değişimini göstermektedir. (10.a) ifadesi EO algoritmasının keşif ve sömürü yeteneğini geliştirirken, arama hızının yavaşlatılarak yakınsamanın garanti altına alınması sağlar. Bu durumda (10.b) ifadesindeki durum dikkate alınmalıdır.

$$
\mathrm{t}=\left(1-\frac{\text { iter }^{\text {iter }_{\text {max }}}}{\mathrm{a}_{2} \cdot\left(\frac{\mathrm{iter}}{\text { iter }_{\text {max }}}\right)}\right.
$$

(10.a) eşitliğinde, $a_{2}$ sabit bir değerdir ve keşif yeteneğinin geliştirilmesinde etkilidir.

$$
\mathrm{t}_{0}=\frac{1}{\lambda} \cdot \ln \left(-\mathrm{a}_{1} \operatorname{sign}\left(\overrightarrow{\mathrm{r}}-\frac{1}{2}\right) \cdot\left(1-\mathrm{e}^{-\vec{\lambda} \mathrm{t}}\right)\right)+\mathrm{t}
$$

(10.b) ifadesindeki $a_{1}$ 'de sabit bir değerdir ve keşif yeteneğini kontrol etmeyi sağlar. $a_{1}$ değerinin yüksek seçilmesi keşif yeteneğini arttırırken diğer sömürü performansının düşmesine sebep olur. Aynı durum $a_{2}$ katsayisi icin gecerlidir. Bu denge göz önüne alınarak yapılan yapılandırma işleminde $a_{1}$ ve $\mathrm{a}_{2}$ degerleri sırasıyla 2 ve 1 olarak alınmıştır. Üçüncü parametre ise, $\operatorname{sign}\left(\overrightarrow{\mathrm{r}}-\frac{1}{2}\right)$ ifadesidir. Bu ifade keşif ve sömürü arasında dengeyi etkiler. $\mathrm{r}$ ifadesi [0-1] arasında rastgele atanmış bir vektördür. $\mathrm{Bu}$ durumda (9) ifadesi (11) eşitliği ile ifade edilebilir.

$$
\overrightarrow{\mathrm{F}}=-\mathrm{a}_{1} \cdot \operatorname{sign}\left(\overrightarrow{\mathrm{r}}-\frac{1}{2}\right) \cdot\left(\mathrm{e}^{-\vec{\lambda} \cdot \mathrm{t}}-1\right)
$$

Adım 4: Üretim Hızı Parametresi

Üretim hızı algoritmanın en önemli terimlerinden bir tanesidir. G değeri sömürü fazını iyileştirerek kesin çözümün sağlanmasında etkili bir rol oynar. Birinci dereceden üstel olarak azalan G değeri (12) eşitliği ile ifade edilir.

$$
\overrightarrow{\mathrm{G}}=\overrightarrow{\mathrm{G}}_{0} \cdot \mathrm{e}^{-\overrightarrow{\mathrm{k}}\left(\mathrm{t}-\mathrm{t}_{0}\right)}
$$

$\mathrm{Bu}$ ifadede; $\mathrm{G}_{0}$-başlangıç değeridir ve k-bozulma sabitini ifade etmektedir. Daha kontrollü arama modeline sahip olmak için $\mathrm{k}=\lambda$ olduğu kabul edilmiştir. Türetilmiş olan $\lambda$ değeri, üstel terimde kullanılır. Böylece, son üretim oranını ifade eden matematiksel eşitlik (13) eşitliği ile gösterilir.

$$
\vec{G}=\vec{G}_{0} \cdot e^{-\vec{\lambda}\left(t-t_{0}\right)}=\vec{G}_{0} \vec{F}
$$

(13) ifadesinde $\overrightarrow{\mathrm{G}}_{0}$ vektör değeri (14) eşitliği ile ifade edilir.

$$
\overrightarrow{\mathrm{G}}_{0}=\overrightarrow{\mathrm{GCP}}\left(\overrightarrow{\mathrm{C}}_{\mathrm{eq}}-\vec{\lambda} \cdot \overrightarrow{\mathrm{C}}\right)
$$

$\overrightarrow{\mathrm{GCP}}$, vektörünün hesaplanması (15)'de belirtilen matematiksel ifade ile tanımlanır. Bu denklemde GCP, üretim döneminin güncelleme sürecine katkı olasılığını içeren üretim kontrol parametresi olarak tanımlanır. Durum güncellemek için kaç parçacığın üretim terimini kullandığını belirleyen bu katkının olasılığ 1 , Üretim Olasılığı (GP) adı verilen başka bir terimle belirlenir. GP $=0.5$ seçildiğinde ile keşif ve sömürü arasında iyi bir denge sağlanır. Bu yüzden, çalışmada GP değeri 0.5 olarak seçilmiştir. 


$$
\overrightarrow{\mathrm{GCP}}=\left\{\begin{array}{cc}
0.5 . \mathrm{r}_{1} & \mathrm{r}_{2} \geq \mathrm{GP} \\
0 & \mathrm{r}_{2}<\mathrm{GP}
\end{array}\right\}
$$

$\mathrm{Bu}$ ifadede, $r_{1}$ ve $r_{2}$ degerleri $[0,1]$ arasinda rastgele olarak değișen rasyonel sayılardır. Tüm bu kabuller dikkate alındığında EO'nun güncelleme kuralı aşağıdaki (16) eşitliği ile tanımlanır.

$$
\overrightarrow{\mathrm{C}}=\overrightarrow{\mathrm{C}}_{\mathrm{eq}}+\left(\overrightarrow{\mathrm{C}}-\overrightarrow{\mathrm{C}}_{\mathrm{eq}}\right) \cdot \overrightarrow{\mathrm{F}}+\frac{\overrightarrow{\mathrm{G}}}{\vec{\lambda} \mathrm{V}}(1-\overrightarrow{\mathrm{F}})
$$

Bu ifadede $F$ değeri (11) denklemine uygun şekilde belirlenmiştir ve $V$ değeri 1 olarak seçilmiştir. $\mathrm{Bu}$ matematiksel ifadede ilk terim denge konsantrasyonudur. İkinci terim ise optimum noktanın belirlenmesi için global arama yapmaktan sorumludur. Bu terim keşif aşamasına daha fazla katkıda bulunur, böylece konsantrasyondaki büyük değişikliklerden faydalanır. Üçüncü terim, çözümü daha doğru hale getirmeye katkıda sağlar. Dolayısıyla bu terim sömürü için daha fazla katkıda bulunur ve üretim oranı ile yönetilen konsantrasyondaki küçük değişikliklerden yararlanır. Her bir parçacık bulunduğu pozisyona uygun olarak bir uygunluk fonksiyonu üretir. İterasyon sonucunda her bir parçacığın uygunluk değeri, önceki iterasyondaki değeri ile karşılaştırılır ve daha iyi bir çözüm sağladığında bulunan değer saklanır. Bu mekanizma sömürü yeteneğine yardımc1 olur, ancak eğer yöntem global keşif yeteneğinden faydalanmıyorsa yerel minimum değerine hapsolma şansını artırabilir. EO algoritmasının sözde kodu Tablo 1'de gösterilmiştir.

Tablo 1. EO algoritmasın sözde kodu.

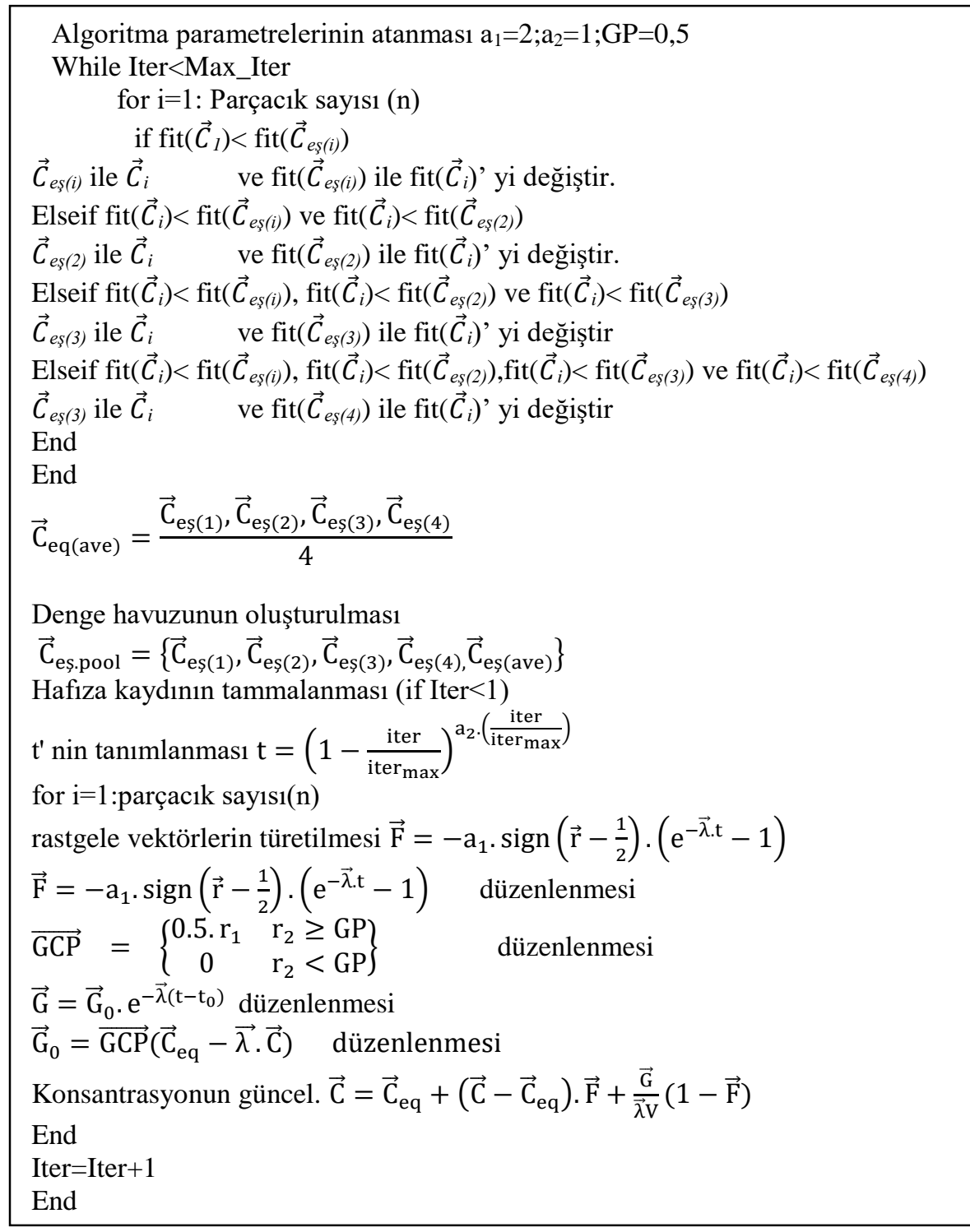




\subsection{Uyum Fonksiyonu}

Uyum fonksiyonu, darbe fonksiyonu, çift üstel fonksiyon ile hesaplanan ve deneysel olarak elde edilen dalga formunun karşılaştırmak için kullanılmıştır. Karşılaştırma metodu olarak toplam karesel hatanın minimum olacak şekilde amaç fonksiyonu belirlenmiştir. Amaç fonksiyonun matematiksel ifadesi (17) eşitliği ile ifade edilir.

$$
F=\int_{0}^{T}\left[V(t, \bar{x})-V_{m}(t)\right]^{2} d t
$$

Bu eşitlikte;

F : Karesel hataların toplamı

$\mathrm{T} \quad$ : Uygulanan akım sinyalinin süresi

$V(t, \bar{x})$ : Matematiksel olarak elde edilen yıldırım akımı dalga formu

$V_{m}(t)$ : Ölçülen yapay yıldırım akımı dalga formu

$\bar{x} \quad$ : Darbe parametrelerinin değişken vektör durumunu ifade eder

(17) eşitliği ayrık formda düşünüldüğünde (18) ifadesi ile tanımlanabilir.

$$
F=\sum_{k=1}^{N}\left[v(k \Delta t, x)-v_{m}(k \Delta t)\right]^{2} \cdot \Delta t
$$

Bu ifadede, $\mathrm{N}$ - ayrık zamanlı örneklerin sayısını ve $\Delta \mathrm{t}$ - örnekleme zamanını ifade etmektedir.

\section{OPTIMIZASYON ANALIZ SONUCLARI}

Yapay yıldırım akımı dalga formu kullanılarak benzetim fonksiyonlarının parametre tahmininde (1922) eşitliklerinde belirtilen sınırlamalar dikkate alınmıştır ve bu sınırlamalara göre optimizasyon algoritmalarının alt üst sınır bant değerleri belirlenmiştir.

$$
\begin{aligned}
0 \leq I & \leq I_{\text {mak }}(A) \quad ;(\operatorname{Imax}=21.5 k A) \\
0 & \leq \tau_{1} \leq 20(\mu \mathrm{s}) \\
10 & \leq \tau_{2} \leq 6000(\mu \mathrm{s}) \\
& \leq \leq n \leq 20
\end{aligned}
$$

Yapay yıldırım dalga formu ile GA, EO algoritmaları ile hesaplanan parametre değerlerine bağlı olarak elde edilen sonuçların istatistiksel olarak değerlendirilmesinde R2 testi kullanılmıştır. R2 ifadesinin matematiksel denklemi (47) eşitliği ile ifade edilir.

$$
R^{2}=\frac{\sum_{i=1}^{n}\left(\hat{y}_{i}-\bar{y}\right)^{2}}{\sum_{i=1}^{n}\left(y_{i}-\bar{y}\right)^{2}}
$$

Bu ifadede, yi- deneysel olarak saptanmış değerler, $\hat{y}_{i}$ regresyon eşitliğinden saptanmış değerler, $\bar{y}$ ise deneysel olarak elde edilen yapay yıldırım akımı dalga formu verilerin ortalamasını ifade etmektedir.

GA ve EO algoritmaları kullanılarak darbe ve çift üstel 20,8 kA' lik yapay yıldırım akımı dalga formunu tanımlamak için hesaplanan fonksiyon parametreleri Tablo 2' de gösterilmiştir. Hesaplanan parametre değerlerine bağlı olarak yıldırım akımı dalga formları ise grafiksel olarak Şekil 4'de sunulmuştur. 


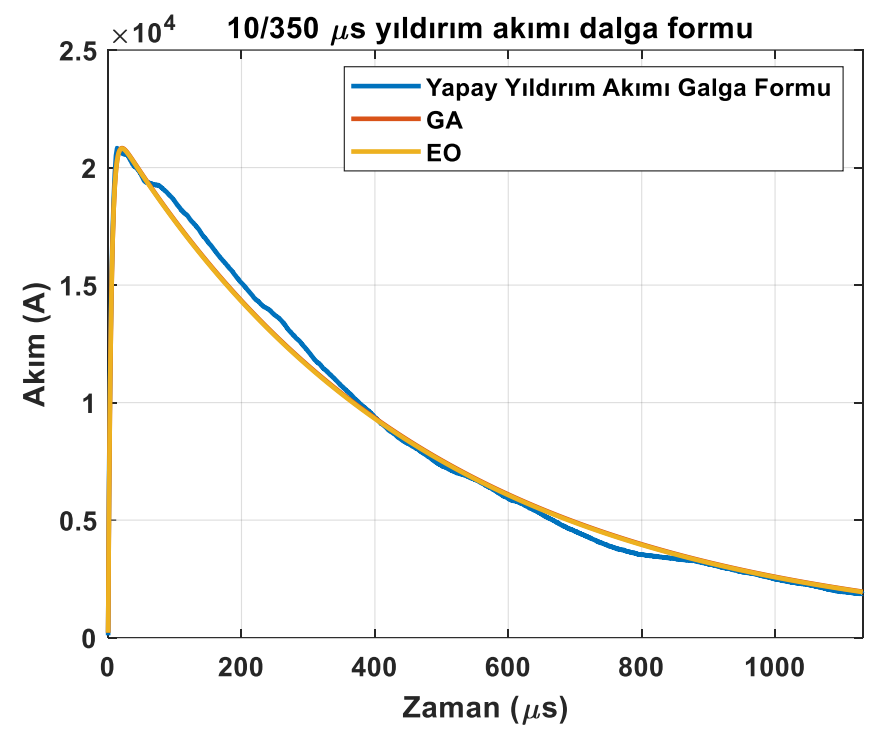

Şekil 4. 10/350 $\mu s^{\prime}$ lik 10,9 kA yapay yıldırım akımı dalga formu ve GA, PSO ve GWO-CS algoritmaları ile hesaplanan fonksiyon parametrelerine bağlı olarak elde edilen yıldırım akımı dalga formlarının zamana göre değişim grafiği.

$\mathrm{R}^{2}$ testi ile elde edilen istatistiksel değerleri desteklemek amacı ile sunulan optimizasyon algoritmaların çalıştırılması ile elde edilen sonuçlara göre Standart sapma (STD), ortalama hata (RE), Kare ortalama kök hata (RMSE) ve ortalama mutlak hata (MAE) değerleri hesaplanarak darbe ve çift üstel fonksiyonları için sunulan optimizasyon algoritmalarının performansı değerlendirilmiştir. STD, RE, RMSE ve MAE değerlerinin hesaplanmasında sırası ile (24-27) denklemleri kullanılır ve bu eşitlikler yardımı ile hesaplanan istatistiksel sonuçlar Tablo 3'de sunulmuştur.

$$
\begin{gathered}
S T D=\sqrt{\frac{\sum_{i=1}^{n}\left(x_{i}-\bar{x}\right)^{2}}{n}} \\
R E=\frac{\sum_{i=1}^{n}\left(x_{i}-\bar{x}\right)}{\bar{x}} * 100 \\
M A E=\frac{\sum_{i=1}^{n}\left(x_{i}-\bar{x}\right)}{n} \\
R M S E=\sqrt{\frac{\sum_{i=1}^{n}\left(x_{i}-\bar{x}\right)}{n}}
\end{gathered}
$$

$\mathrm{Bu}$ eşitliklerde $\mathrm{x}_{\mathrm{i}}$ - i. İterasyonda optimizasyon algoritması ile elde edilen değerleri, $\bar{x}$ ifadesi ise

\begin{tabular}{|c|c|c|c|c|c|c|c|c|}
\hline \multirow{2}{*}{$\begin{array}{c}\text { Benzetim } \\
\text { Fonksiyonu }\end{array}$} & \multirow{2}{*}{$\begin{array}{c}\text { Optimizasyon } \\
\text { Algoritması }\end{array}$} & $\mathbf{k A}$ & \multicolumn{5}{|c|}{ Hesaplanan fonksiyon parametreleri } & \multirow{2}{*}{$\frac{\text { İstatistiksel }}{\mathrm{R}^{2}}$} \\
\hline & & $I$ & $I_{m a k}$ & $\tau_{1}(\mu \mathrm{s})$ & $\tau_{2}(\mu \mathrm{s})$ & $\mathrm{n}$ & $\eta$ & \\
\hline \multirow{2}{*}{ Darbe Fonksiyonu } & GA & $\begin{array}{c}20,82 \\
8\end{array}$ & $\begin{array}{c}21,8 \\
2\end{array}$ & 5,46 & 466,30 & 0,82 & $\begin{array}{c}0,94 \\
4\end{array}$ & 0,99957 \\
\hline & EO & $\begin{array}{c}20,82 \\
8\end{array}$ & $\begin{array}{c}21.8 \\
2\end{array}$ & 5.52 & 463.83 & 0,76 & $\begin{array}{c}0,93 \\
9\end{array}$ & 0,99964 \\
\hline \multirow[t]{2}{*}{$\begin{array}{c}\text { Çift Üstel } \\
\text { Fonksiyon }\end{array}$} & GA & $\begin{array}{c}20,82 \\
8\end{array}$ & $\begin{array}{c}21,8 \\
2\end{array}$ & 5,36 & 465,2 & $-94,17$ & - & 0,99953 \\
\hline & EO & $\begin{array}{c}20,82 \\
8\end{array}$ & $\begin{array}{c}21,8 \\
2\end{array}$ & 4,43 & 467,42 & $-94,73$ & - & 0,99955 \\
\hline
\end{tabular}
yapay yıldırım akımı dalga formunun örnek sayısına bağlı olarak ortalama değerini ifade eder.

Tablo 2. 20,8 kA yapay yıldırım akımı dalga formu için GA ve EO algoritmaları ile hesaplanan fonksiyon parametreleri. 
Tablo 3. Darbe fonksiyon ile elde edilen sonuçların istatistiksel olarak karşılaştırılması.

\begin{tabular}{c|cccc|} 
Algorithm & STD & RE & MAE & RMSE \\
\cline { 1 - 4 } GA & $5.868 \mathrm{e}-2$ & $8.27 \mathrm{E}-10$ & $4.32 \mathrm{e}-11$ & $6,37 \mathrm{e}-6$ \\
\cline { 1 - 1 } EO & $5.354 \mathrm{e}-2$ & $2.35 \mathrm{e}-10$ & $5.44 \mathrm{e}-12$ & $4.48 \mathrm{e}-6$ \\
\hline
\end{tabular}

\section{SONUÇLAR}

Bu çalışmada yıldırım darbelerinin modellenmesinde yaygın olarak kullanılan Darbe ve Çift üstel fonksiyonların parametre değerlerinin belirlenmesinde optimizasyon tabanlı bir yaklaşım sunulmuştur. Yapay yıldırım akım dalga formu olarak Dresden Yüksek Gerilim Test Teknolojisinde (IP176/12S) deneysel olarak ölçülen 10/350 $\mu$ s'lik 20,8 kA genliğe sahip yıldırım akım dalga formu kullanılmıştır. Elde edilen sonuçlar optimizasyon tabanlı parametre belirleme yaklaşımının Darbe fonksiyonu ve Çift üstel fonksiyon için yüksek doğrulukta hesaplama yeteneğine sahip olduğunu göstermektedir. İstatistiksel sonuçlar Darbe fonksiyonun yapay yıldırım akımını tanımlamada çift üstel modele göre daha yüksek doğruluk seviyesine sahip olduğu görülmektedir. Ayrıca EO algoritması ile hesaplanan parametre değerlerinin istatistiksel olarak GA ile elde edilen değerler ile karşılaştırıldığında $S T D=5.354 \mathrm{e}-2, \mathrm{RE}=2.35 \mathrm{E}-10, \mathrm{MAE}=5.44 \mathrm{e}-12$ ve $\mathrm{RMSE}=4.48 \mathrm{E}-6$ değerleri ile daha iyi sonuçlar verdiği görülmektedir.

Sunulan yaklaşım farklı genlik ve karakteristik yapıya sahip yıldırım akımı dalga formlarını tanımlamada ve yıldırım dalga formunu tanımlamada literatürde sunulan matematiksel fonksiyonların parametrelerinin belirlenmesinde kullanılabilir.

Gelecek çalışmalarda, farklı Meta-sezgisel optimizasyon algoritmalarının yıldırım dalga formunu tanımlamadaki performansı değerlendirilerek, $1.2 / 50$ ve $8 / 20 \mu \mathrm{s}^{\prime}$ lik yıldırım akımı dalga formlarının parametrenin hesaplanması planlanmaktadır. Hesaplanan parametreler yardımı ile yıldırım akımların uçaklar, iletim ve haberleşme hatlarında oluşturacağ 1 geçici durumların bilgisayar ortamımda analiz edilebilmesi ve incelenebilmesi planlanmaktadır.

\section{TEŞEKKÜR}

Yazarlar, çalışmada kullanılan yapay yıldırım akımı dalga formunu açık erişim olarak paylaşan Dresden Yüksek Gerilin Test Teknolojisine (IP176/12S) teşekkürlerini sunmaktadır.

\section{REFERANSLAR}

Al-Hasawi W. M. and El-Naggar K. M. (2003) "A genetic based algorithm for digitally recorded impulse parameter estimation," 2003 IEEE Bol. PowerTech - Conf. Proc., vol. 2, pp. 804-808, doi: 10.1109/PTC.2003.1304650.

Anderson A. J, Eriksson R. B. (1979) “Lightning Parameters for Engineering Application,” Electra, vol. 69, pp. 65-102.

Berger H, Anderson K, Kröninger R. B. (1980) "Parameters of lightning flashes," Electra, vol. 41, pp. 23-37, 1975.

Borghetti A, Gutierrez J. A, Nucci C. A. (2004) M. Paolone, E. Petrache, and F. Rachidi, "Lightninginduced voltages on complex distribution systems: Models, advanced software tools and experimental validation," J. Electrostat., vol. 60, no. 2-4, pp. 163-174, doi: 10.1016/j.elstat.2004.01.001.

Chen Y, Liu S, Wu X. and Zhang F. (2002) "A new kind of lightning channel-base current function," IEEE Int. Symp. Electromagn. Compat., vol. 2002-Janua, no. 1, pp. 304-307, doi: 10.1109/ELMAGC.2002.1177430.

Elmas Ç. (2007) Yapay Zeka Uygulamaları, Birinci Ba. Seçkin Yayıncılık. 
Elrodesly K. (2010) "Comparison Between Heidler Function And The Pulse Function For Modeling The Lightning Return-Stroke Current Comparison between Heidler Function and the Pulse Function for Modeling the Lightning Return-Stroke Current By,"

Elrodesly K. and Hussein A. M. (2010) "Modelling The Lightning Return-Stoke Current Using Heidler Function", 30th International Conference on Lightning Protection (ICLP).

Faramarzi A, Mohammad H, Brent S. and Mirjalili S. (2020) "Equilibrium Optimizer:A Novel Optimization Algorithm", Knowladge-Based Systems.

Franzel J. F. (1993) "Genetic Algorithms," IEEE Potentials, vol. 12, no. 3, pp. 21-24, doi: $10.1109 / 45.282292$.

Gamerota W. R, Elismé J. O, Uman M. A. and Rakov V. A. (2012) "Current waveforms for lightning simulation," IEEE Trans. Electromagn. Compat., vol. 54, no. 4, pp. 880-888, doi: 10.1109/TEMC.2011.2176131.

Heidler F, Cvetić J. M. and Stanić B. V. (1999) "Calculation of lightning current parameters," IEEE Trans. Power Deliv., vol. 14, no. 2, pp. 399-404, doi: 10.1109/61.754080.

Leteinturier C, Weidman C. and Hamelin J. (1990) "Current and electric field derivatives in triggered lightning return strokes," J. Geophys. Res., vol. 95, no. D1, pp. 811-828, doi: 10.1029/JD095iD01p00811.

Lewin P. L, Tran T. N, Swaffield D. J. and Hällström J. K. (2008) "Zero-phase filtering for lightning impulse evaluation: A K-factor filter for the revision of IEC60060-1 and -2," IEEE Trans. Power Deliv., vol. 23, no. 1, pp. 3-12, doi: 10.1109/TPWRD.2007.911124.

Lin, Y.T., Uman, M.A., Tiller, "characterization of lightning return stroke electric and magnetic fields from simultaneous two-station measurement," J. Geophys. Res., vol. 84, no. 10, pp. 6307-6314.

Machts R, Hunold A, Drebenstedt C, Rock M, Leu C. and Haueisen J. (2019) "Measurement and analysis of partial lightning currents in a head phantom," PLoS One, vol. 14, no. 9, pp. 1-22, doi: 10.1371/journal.pone.0223133.

McComb T. R. and Lagnese J. E. (1991) "Calculating the parameters of full lightning impulses using model-based curve fitting," IEEE Trans. Power Deliv., vol. 6, no. 4, pp. 1386-1394, doi: $10.1109 / 61.97668$.

Paolone M, Nucci C. A, Petrache E. and Rachidi F. (2004) "Mitigation of Lightning-Induced Overvoltages in Medium Voltage Distribution Lines by Means of Periodical Grounding of Shielding Wires and of Surge Arresters: Modeling and Experimental Validation," IEEE Trans. Power Deliv., vol. 19, no. 1, pp. 423-431, doi: 10.1109/TPWRD.2003.820196.

Paolone M, Nucci C. A, and Rachidi F. (2001) "A new finite difference time domain scheme for the evaluation of lightning induced overvoltages on multiconductor overhead lines," 5th Int. Conf. Power Syst. transients, Rio Janeiro, Brazil, no. October 2014, pp. 1-7.

Protection againts Lightning Part 1: General Prenciple, IEC Standard 62305, 2nd Edition, 2010.Rakov V. A. (2001) "Transient response of a tall object to lightning," IEEE Trans. Electromagn. Compat., vol. 43, no. 4, pp. 654-661, doi: 10.1109/15.974646.

Willett J. C, Bailey J. C, Idone V. P, Eybert-Berard A. and Barret L. (1989) "Submicrosecond intercomparison of radiation fields and currents in triggered lightning return strokes based on the transmission-line model," J. Geophys. Res., vol. 94, no. D11, doi: 10.1029/jd094id11p13275.

Wong K. C. P, Ryan H. M, Tindle J, Blackett J. and Watts M. W. (1999) "Digital measurement of lightning impulse parameters using curving fitting algorithms," IEE Conf. Publ., vol. 1, no. 467, doi: 10.1049/cp:19990540. 